University of Nebraska - Lincoln

DigitalCommons@University of Nebraska - Lincoln

USGS Staff -- Published Research

US Geological Survey

2017

\title{
Comparison of Acoustic Recorders and Field Observers for Monitoring Tundra Bird Communities
}

Skyler T. Vold

Montana State University

Colleen M. Handel

U.S. Geological Survey, cmhandel@usgs.gov

Lance B. McNew

Montana State University

Follow this and additional works at: http:// digitalcommons.unl.edu/usgsstaffpub

Part of the Geology Commons, Oceanography and Atmospheric Sciences and Meteorology Commons, Other Earth Sciences Commons, and the Other Environmental Sciences Commons

Vold, Skyler T.; Handel, Colleen M.; and McNew, Lance B., "Comparison of Acoustic Recorders and Field Observers for Monitoring Tundra Bird Communities" (2017). USGS Staff-- Published Research. 1003.

http://digitalcommons.unl.edu/usgsstaffpub/1003

This Article is brought to you for free and open access by the US Geological Survey at DigitalCommons@University of Nebraska - Lincoln. It has been accepted for inclusion in USGS Staff -- Published Research by an authorized administrator of DigitalCommons@University of Nebraska - Lincoln. 
Tools And Technology

\title{
Comparison of Acoustic Recorders and Field Observers for Monitoring Tundra Bird Communities
}

\author{
SKYLER T. VOLD, ${ }^{2}$ U.S. Geological Survey, Alaska Science Center, 4210 University Drive, Anchorage, AK 99508, USA \\ COLLEEN M. HANDEL (iD ${ }^{1}$ U.S. Geological Survey, Alaska Science Center, 4210 University Drive, Anchorage, AK 99508, USA \\ LANCE B. McNEW, ${ }^{2}$ U.S. Geological Survey, Alaska Science Center, 4210 University Drive, Anchorage, AK 99508, USA
}

\begin{abstract}
Acoustic recorders can be useful for studying bird populations but their efficiency and accuracy should be assessed in pertinent ecological settings before use. We investigated the utility of an acoustic recorder for monitoring abundance of tundra-breeding birds relative to point-count surveys in northwestern Alaska, USA, during 2014. Our objectives were to 1) compare numbers of birds and species detected by a field observer with those detected simultaneously by an acoustic recorder; 2) evaluate how detection probabilities for the observer and acoustic recorder varied with distance of birds from the survey point; and 3) evaluate whether avian guild-specific detection rates differed between field observers and acoustic recorders relative to habitat. Compared with the observer, the acoustic recorder detected fewer species $\left(\beta_{\text {Method }}=-0.39 \pm 0.07\right)$ and fewer individuals $\left(\beta_{\text {Method }}=-0.56 \pm 0.05\right)$ in total and for 6 avian guilds. Discrepancies were attributed primarily to differences in effective area surveyed $(91 \%$ missed by device were $>100 \mathrm{~m}$ ), but also to nonvocal birds being missed by the recorder (55\% missed $<100 \mathrm{~m}$ were silent). The observer missed a few individuals and one species detected by the device. Models indicated that relative abundance of various avian guilds was associated primarily with maximum shrub height and less so with shrub cover and visual obstruction. The absence of a significant interaction between survey method (observer vs. acoustic recorder) and any habitat characteristic suggests that traditional point counts and acoustic recorders would yield similar inferences about ecological relationships in tundra ecosystems. Pairing of the 2 methods could increase survey efficiency and allow for validation and archival of survey results. Published 2017. This article is a U.S. Government work and is in the public domain in the USA.
\end{abstract}

KEY WORDS acoustic recorder, detection probability, habitat, passerines, point counts, population monitoring, shorebirds, subarctic Alaska, survey techniques, tundra.

Automated acoustic recording devices are increasingly being recognized as a useful tool for studying bird and anuran populations across broad landscapes because of the capacity of recorders to collect large amounts of vocalization data (Haselmayer and Quinn 2000, Acevedo and VillanuevaRivera 2006, Hutto and Stutzman 2009, Furnas and Callas 2015, Sidie-Slettedahl et al. 2015). Up to $94 \%$ of birds recorded during point counts are detected aurally by field observers, suggesting utility of acoustic recorders for ornithological research and monitoring (Simons et al. 2007). Advantages of automated recorders include the programmable collection of acoustic data $24 \mathrm{hr} /$ day without a skilled observer in the field, thus maximizing sampling effort

Received: 26 May 2016; Accepted: 1 April 2017

Published: 26 July 2017

\footnotetext{
${ }^{1}$ E-mail: cmhandel@usgs.gov

${ }^{2}$ Present affliation: Montana State University, Department of Animal and Range Sciences, Bozeman, MT 55901, USA.
}

and providing controlled spatial and temporal replication for monitoring (Haselmayer and Quinn 2000, Hobson et al. 2002, Acevedo and Villanueva-Rivera 2006). An additional advantage is elimination of inter-observer errors because all recordings can be analyzed by a single qualified interpreter; this individual's analysis can be validated by other interpreters (Hobson et al. 2002, Rempel et al. 2005, Celis-Murillo et al. 2009). In contrast to field observations, recordings can be rechecked repeatedly by ear and with spectrograms. This capability makes acoustic recorders especially useful for surveys during periods of very high bird activity, such as the dawn chorus, because a field observer's ability to detect birds can decline by $50 \%$ as bird density increases (Bart and Schoultz 1984).

Despite advantages of acoustic recorders for surveying birds, relatively little information exists about detection rates of recorders relative to those of actual field observers (Sidie-Slettedahl et al. 2015). Acoustic recorders are unable to detect nonvocalizing birds, suggesting species-specific biases in detectability. Without triangulation to determine 
position of birds in the survey area or visual observations to detect moving birds, it is often difficult to discern from a recording how many individuals of a species may be vocalizing in the survey area. Thus, occurrence at a site is often reduced to presence-absence for a species instead of quantified as abundance. In addition, the effective sampling distance of aurally detected birds may differ from that of a field observer; this detection bias may vary with survey and habitat conditions (Furnas and Callas 2014, McNew and Handel 2015). Although acoustic devices may record fewer detections, especially for nonvocal species, they may have utility as a supplement to, or replacement for, field observers if the difference between methods in detection rates is consistent across variable environmental conditions. Thus, information on spatially variable detection rates and the effective survey distance of acoustic recorders is needed to design surveys and facilitate statistical analyses (Hutto and Stutzman 2009). Previous research has shown that acoustic recorders often perform as well as, or better than, field observers at measuring species diversity (Haselmayer and Quinn 2000, Acevedo and Villanueva-Rivera 2006) and often have greater detection rates than human observers when many individuals of various species are vocalizing simultaneously (Celis-Murillo et al. 2009). Nevertheless, acoustic recorders have also been found to perform poorly relative to trained field observers during songbird surveys in densely forested landscapes, suggesting that additional work is needed to evaluate relative biases of acoustic recorders in other habitat types and under spatially variable survey conditions (Hutto and Stutzman 2009).

We conducted a series of point-count surveys of tundrabreeding birds in northwestern Alaska, USA, using a trained field observer and an acoustic recorder simultaneously across habitats with varying shrub conditions. We were interested in the potential use of programmable acoustic recorders as a tool to assess seasonal patterns of avian abundance across a broad array of tundra habitats, which are difficult and expensive to survey with human observers. Our objectives were to 1) compare the numbers of tundra-breeding birds and species detected by a field observer with those detected simultaneously by an acoustic recorder; 2) evaluate how detection probabilities for the observer and the acoustic recorder varied with distance of birds from the survey point; and 3) evaluate whether avian guild-specific detection rates differed between field observers and acoustic recorders relative to shrub characteristics. We predicted that a human observer would detect more birds and species overall than an acoustic recorder because the device would miss nonvocalizing birds. We also predicted that careful analysis of acoustic recordings would likely detect some birds missed by the field observer during periods of high song activity. Finally, we predicted that detection rates of different bird guilds would vary relative to shrub characteristics at survey sites due to effects on both abundance and detection probability. We were particularly interested in determining whether differences in detection rates of acoustic recorders and field observers would vary depending on shrub characteristics, which would render acoustic recorders less useful in the absence of correction for habitat-specific detection probability.

\section{STUDY AREA}

The Seward Peninsula of northwestern Alaska encompasses the transition zone between the interior boreal forest and Arctic tundra biomes. The $53,000-\mathrm{km}^{2}$ peninsula is characterized by latitudinal, longitudinal, and elevational gradients in ecosystem types, with a diversity of avian habitats across a relatively limited spatial extent (Kessel 1989). Vegetation classes range from high-elevation alpine tundra to tidally influenced marshlands and lowland boreal forest, with a variety of shrub-dominated vegetation of varying heights $(<10 \mathrm{~cm}$ to $>5 \mathrm{~m})$ at intermediate elevations (Hanson 1953, Swanson et al. 1985). Permafrost condition varies from continuous ( $>90 \%$ coverage) to absent, and a warming climate has resulted in a significant degradation of permafrost and alteration of hydrology during the past 50 years (Yoshikawa and Hinzman 2003). Climate on the Seward Peninsula is characterized by long cold winters $(-20$ to $-30^{\circ} \mathrm{C}$ ), and the growing season (May-Sep) is cool and wet along the coast with warmer and drier conditions inland (Hammond and Yarie 1996). Precipitation increases along a north-south gradient during all seasons and over an elevational gradient in the winter. Average climate records for Nome (a coastal weather station) indicated consistent growing-season daily temperatures $\left(7.7 \pm 5.5^{\circ} \mathrm{C}\right)$ and precipitation $(0.4 \pm 0.02 \mathrm{~cm} /$ day $)$ during the past 25 years.

We sampled birds and vegetation at 59 sites separated by $\geq 500 \mathrm{~m}$ along 5 transects, which were selected in accessible areas from a larger collection of transects used for long-term avian monitoring on the Seward Peninsula (McNew et al. 2013; Thompson et al. 2016, 2017). Transects were located near Grant Creek $\left(65.54^{\circ} \mathrm{N}, 165.05^{\circ} \mathrm{W}\right)$, Neva Creek $\left(65.48^{\circ} \mathrm{N}, 164.76^{\circ} \mathrm{W}\right)$, Bunker Hill $\left(65.15^{\circ} \mathrm{N}, 164.75^{\circ} \mathrm{W}\right)$, Horton Creek $\left(65.69^{\circ} \mathrm{N}, 164.03^{\circ} \mathrm{W}\right)$, and Fox River $\left(64.84^{\circ} \mathrm{N}, 163.76^{\circ} \mathrm{W}\right)$. Survey points ranged in elevation from $50 \mathrm{~m}$ to $458 \mathrm{~m}$ and encompassed gradients of physical and biotic habitat conditions ranging from dwarf shrub mat tundra at higher elevations to mixed stands of tall shrubs and sparse woodlands along lowland margins of the boreal forest (Fig. 1).

\section{METHODS}

\section{Field Procedures}

A single experienced observer (SV) conducted 1-3 10-min point counts while simultaneously recording all bird sounds with an acoustic recording device at each of the 59 survey sites during the peak breeding season between 1 and 17 June 2014. After arrival at each survey site, the observer mounted a commercially available recorder (Model SM2; Wildlife Acoustics, Inc., Maynard, MA, USA) on a tripod at a height of $1 \mathrm{~m}$. Additional foam covers were attached to the recorder's 2 omnidirectional microphones to minimize interference from wind and rain noise. Before beginning each survey, the observer recorded cloud cover, ambient air temperature, wind speed, and precipitation, and announced 


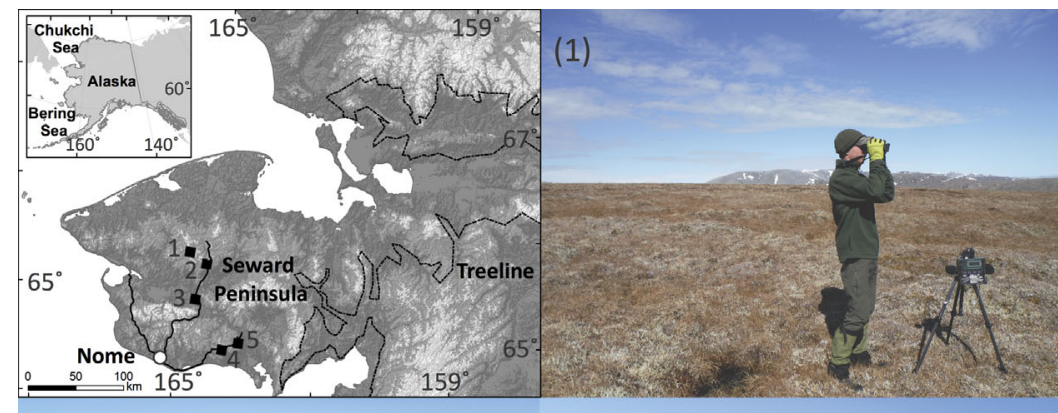

(2)

(3)

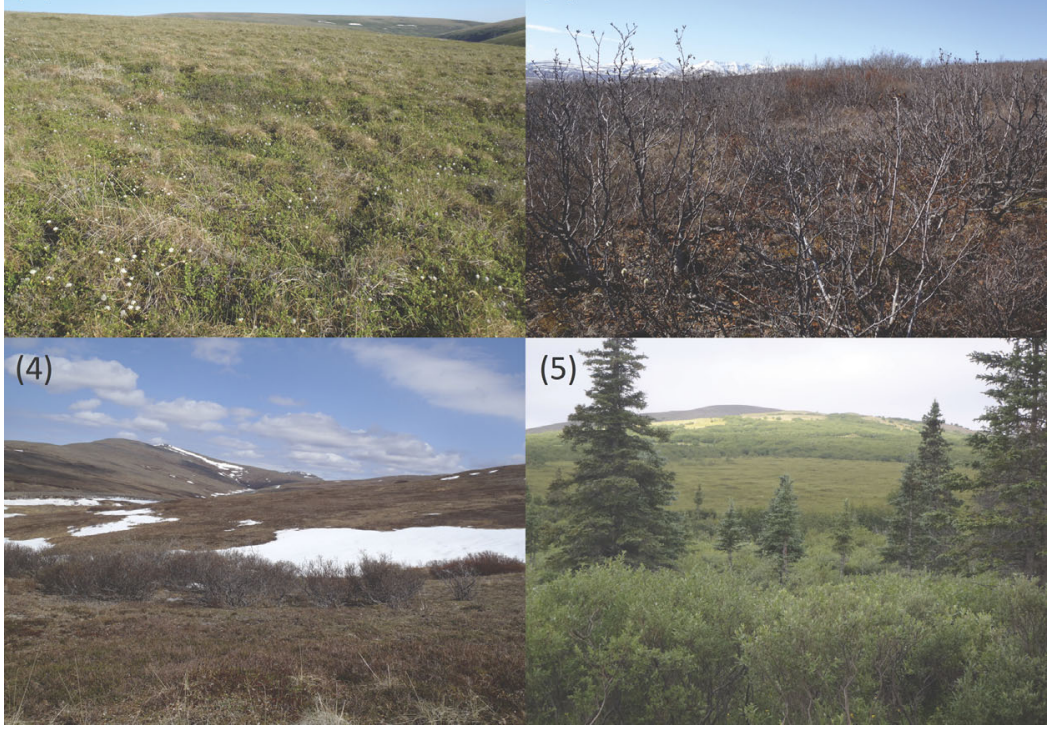

Figure 1. Location of avian survey areas during 2014 on the Seward Peninsula, northwestern Alaska, USA. Photographs illustrate the range of habitats in the Arctic-boreal transition zone sampled in this study: 1) First author (SV) with acoustic recorder at Grant Creek (elevation $458 \mathrm{~m}$ ), dwarf shrub mat tundra, dominated by lichens, herbaceous, graminoid, and low ericaceous vegetation; 2) Neva Creek (131 m), dwarf shrub meadow, dominated by tussock-forming cottongrass (Eriophorum spp.) and other sedges, interspersed with low ericaceous shrubs, dwarf birch (Betula spp.), and dwarf willow (Salix spp.); 3) Bunker Hill $(106 \mathrm{~m})$, medium shrub thicket, dominated by stands of alder (Alnus viridis), willow, dwarf birch and ericaceous shrubs, interspersed with graminoid vegetation; 4) Horton Creek ( $239 \mathrm{~m}$ ), sparse stands of low shrub thicket (primarily willow $<1 \mathrm{~m}$ tall) across dwarf shrub mat tundra; and 5) Fox River (53 m), coniferous woodland and tall shrub thicket, with sparse white spruce (Picea glauca) in matrix of tall willows $(>2.5 \mathrm{~m}$ tall).

into the recorder's microphone the survey site, date, and time. Surveys were not conducted if wind speed exceeded $15 \mathrm{~km} / \mathrm{hr}$, fog limited visibility to $<250 \mathrm{~m}$, or there was more than a light rain shower. Surveys were conducted using a standard point-count protocol in which all individual birds detected by sight or sound were identified to species (Ralph et al. 1995). For each individual bird detected, the observer recorded 1) distance to the bird in intervals of $0-25 \mathrm{~m}$, 26-50 m, 51-100 m, 101-250 m, and $\geq 250 \mathrm{~m}$; 2) minute of the survey during which the bird was first detected; and 3) vocalization type and behavior when the bird was first detected. Vocalization, when given, was recorded as full song, partial song, call, alarm call, or winnow; behavior of observed birds was recorded as flying, flight display, feeding, sitting, or walking. Data were collected under a study plan with procedures approved by the U.S. Geological Survey Alaska Science Center's Animal Care and Use Committee (protocol 2012-9).

Vertical structure, density, and diversity of shrubs can influence both the occurrence and detectability of birds in Arctic and subarctic ecosystems (Kessel 1989, Amundson et al. 2014, McNew and Handel 2015). To test for such associations, we measured 9 vegetation characteristics related to shrubs at 10 subsampling points associated with each bird survey location immediately after all bird surveys had been completed for the season (29 Jun-21 Jul 2014). We placed 5 subsampling plots along each of $220-\mathrm{m}$ transects oriented in a random direction $\left(0-359^{\circ}\right)$; one transect originated at the bird survey point and the other began at a point selected randomly within $250 \mathrm{~m}$ of the bird survey point. At each subsampling point, we measured height of the tallest shrub (to $0.01 \mathrm{~m}$ ) and estimated overlapping coverages within a $0.5-\mathrm{m} \times 0.5-\mathrm{m}$ quadrat frame for 4 types of shrub: alder (Alnus viridis), dwarf birch (Betula spp.), ericaceous shrubs (e.g., Empetrum, Vaccinium spp.), and willow (Salix spp.). Percent cover was categorized as $0 \%, 1-5 \%, 6-25 \%, 26-50 \%$, $51-75 \%, 76-95 \%$, or $96-100 \%$ of the quadrat frame; we converted these to the midpoints of each category for analysis. We also measured visual obstruction, an index of vegetation height and density ranging from 0 to 5 , at each subsampling point from a distance of $2 \mathrm{~m}$ and height of $0.5 \mathrm{~m}$ as described in Robel et al. (1970). 


\section{Laboratory Analysis}

We downloaded acoustic files from the recorder's memory card and converted them into .wav format with Kaleidoscope Converter software (Wildlife Acoustics, Inc.). To eliminate inter-observer bias, the same observer (SV) who conducted the point-count surveys in the field analyzed the acoustic recordings. The analyst located the 10-min recording windows that corresponded with simultaneous 10-min point counts, and recorded the survey site, date, and start time of the recording. For each distinguishable bird heard producing an identifiable vocalization, the analyst recorded species, type of vocalization, and the minute within the 10-min sound file during which the vocalization was first detected. Each individual bird was counted only once, regardless of how many times it vocalized during the 10-min recording or how much of a vocalization was recorded. When multiple individuals of the same species were heard vocalizing simultaneously, they were counted as separate individuals. Nonoverlapping songs were always treated as the same individual because of the potential for undetected movement; thus, our conservative protocol likely resulted in negative bias in the number of individuals of some species detected at each site. Although each recording was listened to one time, segments of the recording were often replayed during the listening session to distinguish multiple birds that were vocalizing simultaneously. The analyst, who had 2 years of field experience on the study area and was familiar with the birds and local dialects, spent $12-13 \mathrm{~min}$ to listen to, and record data from, each 10 -min recording.

For each bird detected on a recording, we matched it to the individual detected during the point count that it was most likely to be and assigned it to the same distance class. We assumed that birds vocalizing closer to the recording device would have a greater likelihood of being recorded relative to more distant birds. Therefore, we assigned birds detected on recordings to distance classes determined by field observations beginning with those detected closest to the survey point. For example, if 3 individuals of a species were recorded during the point-count survey at $50 \mathrm{~m}, 100 \mathrm{~m}$, and $250 \mathrm{~m}$ and 2 were identified on the acoustic recording, we assumed that the 2 birds recorded by the device were those detected at $50 \mathrm{~m}$ and $100 \mathrm{~m}$ by the field observer and that the bird occurring at $250 \mathrm{~m}$ was not detected by the acoustic recorder.

\section{Data Analysis}

We performed all statistical analyses in Program R (version 3.0.2; R Core Team 2013). We used distance models to estimate the probability that an individual bird would be detected within $250 \mathrm{~m}$ by the human observer or by the acoustic recorder (Buckland et al. 2001; R package "Distance"). We analyzed all birds together, regardless of species, because of limited sample sizes in this exploratory study. Although there was heterogeneity among species in detection probability, interspecific differences were minimal close to the recorder; thus, overall model estimates should be pooling robust (Burnham et al. 2004). We treated detections of groups of birds as single detections to avoid pseudoreplication, ignoring the potential effect of flock size on detection probability because there were so few $(6.2 \%$ of detections by observer; $3.6 \%$ by acoustic recorder). We used a half-normal function with cosine adjustment terms to model the detection probabilities.

To examine the potential effects of survey method and shrub characteristics on number of birds and species detected at each survey point, we pooled our species-level observation data into 6 groups representing guilds of breeding birds with similar ecological niches, behavior, and vocalization characteristics and limited to those with sufficient detections to model (Table 1). Groups included shorebirds (Charadriidae and Scolopacidae), thrushes and Old World flycatchers (Turdidae and Muscicapidae), longspurs (Calcariidae), Old and New World warblers (Phylloscopidae and Parulidae), sparrows (Emberizidae), and redpolls (Fringillidae).

For each survey point, we constructed 3 composite variables to represent different characteristics of shrub vegetation within the 250-m-radius sampling area around the point. We calculated VO, which represented an index of average vegetation height and density, as the mean visual obstruction index across the 10 subsamples/point. We derived cover, which provided an index of total shrub cover, by summing the percent cover for the 4 shrub types (birch, willow, alder, ericaceous) in each subsample and then calculating the mean across the 10 subsamples. MaxHt was the maximum height (m) of any shrub type across all 10 subsamples.

We used paired $t$-tests (R package "stats") to compare the number of species detected per transect and per point by the field observer vs. the acoustic recorder. We then used generalized linear models with the log-link function and a Poisson error structure (R package "glm") to evaluate how survey method and shrub characteristics affected naïve species richness and the number of birds counted in each bird group. We restricted these analyses to data collected during the first visit to each point to assure independence of counts. We created 12 candidate models representing our hypotheses regarding the effects of survey method and shrub characteristics on the number of birds and species detected. These models were 1) null model, no effect of survey method or shrub characteristics; 2) method-only model, counts of birds differed by method but were unrelated to shrub characteristics; (3-9) method + shrub models, counts of birds differed between methods but also varied with one or more shrub characteristics in an additive fashion; and (10-12) method $\times$ shrub simple interaction models, the effect of one of the shrub characteristics on counts of birds differed between methods. Support for an interaction model would suggest limited utility of a particular method when site-specific habitat conditions influence detection rates. We used Akaike's Information Criterion adjusted for small sample sizes $\left(\mathrm{AIC}_{c}\right)$ to evaluate support for each model (Burnham and Anderson 2002). For models with $\Delta \mathrm{AIC}_{c} \leq 2$ that differed from the top model by a single parameter $(K)$, we considered the additional parameter to be uninformative (Burnham and Anderson 2002, Arnold 2010). Original data and associated metadata have been archived at: doi:10.5066/F7V98674. 
Table 1. Species, ecological groups for analysis, and counts of breeding birds detected by field observers and acoustic recorders during point-count surveys on tundra habitats at 59 sites on the Seward Peninsula, northwestern Alaska, USA, 2014.

\begin{tabular}{|c|c|c|c|c|}
\hline \multirow[b]{2}{*}{ Group } & \multirow[b]{2}{*}{ Species } & \multirow[b]{2}{*}{ Scientific name } & \multicolumn{2}{|c|}{ No. detected } \\
\hline & & & Field observer & Acoustic recorder \\
\hline \multirow[t]{6}{*}{ Shorebirds } & American golden-plover & Pluvialis dominica & 14 & 8 \\
\hline & Pacific golden-plover & Pluvialis fulva & 8 & 6 \\
\hline & Whimbrel & Numenius phaeopus & 2 & 0 \\
\hline & Bristle-thighed curlew & Numenius tahitiensis & 5 & 2 \\
\hline & Western sandpiper & Calidris mauri & 12 & 3 \\
\hline & Wilson's snipe & Gallinago delicata & 59 & 33 \\
\hline \multirow[t]{4}{*}{ Thrushes and bluethroat } & Bluethroat & Luscinia svecica & 24 & 11 \\
\hline & Gray-cheeked thrush & Catharus minimus & 61 & 35 \\
\hline & American robin & Turdus migratorius & 32 & 15 \\
\hline & Varied thrush & Ixoreus naevius & 17 & 13 \\
\hline Longspurs & Lapland longspur & Calcarius lapponicus & 67 & 27 \\
\hline \multirow[t]{7}{*}{ Old and New World warblers } & Arctic warbler & Phylloscopus borealis & 20 & 14 \\
\hline & Northern waterthrush & Parkesia noveboracensis & 30 & 18 \\
\hline & Orange-crowned warbler & Oreothlypis celata & 16 & 9 \\
\hline & Yellow warbler & Setophaga petechia & 31 & 20 \\
\hline & Blackpoll warbler & Setophaga striata & 10 & 7 \\
\hline & Yellow-rumped warbler & Setophaga coronata & 0 & 1 \\
\hline & Wilson's warbler & Cardellina pusilla & 23 & 17 \\
\hline \multirow[t]{5}{*}{ Sparrows } & American tree sparrow & Spizelloides arborea & 16 & 10 \\
\hline & Savannah sparrow & Passerculus sandwichensis & 57 & 31 \\
\hline & Fox sparrow & Passerella iliaca & 118 & 87 \\
\hline & White-crowned sparrow & Zonotrichia leucophrys & 17 & 8 \\
\hline & Golden-crowned sparrow & Zonotrichia atricapilla & 52 & 39 \\
\hline Redpolls & Common and hoary redpoll & Acanthis flammea and A. hornemanni & 162 & 88 \\
\hline Other species & & & 62 & 20 \\
\hline Total birds & & & 915 & 522 \\
\hline
\end{tabular}

\section{RESULTS}

The field observer detected 915 birds representing 38 species at the 59 survey points during the first visit to each site (Table S1, available online in Supporting Information). Overall, 500 (55\%) of the birds detected by the observer in the field were also detected on the acoustic recordings. In addition, 22 individual birds representing 13 species, including 1 new species, were identified from acoustic recordings that were not recorded by the field observer. The proportion of birds detected by the field observer that were also detected by the acoustic recorder declined with distance from the survey point, from $84 \%$ for birds in the $0-25-\mathrm{m}$ interval to $28 \%$ for birds observed $\geq 250 \mathrm{~m}$ from the survey point (Fig. 2). For all species combined, the overall probability of detecting a bird (or flock) within $250 \mathrm{~m}$ was $0.15 \pm 0.01$ (SE) for the human observer and $0.10 \pm 0.009$ for the acoustic recorder, based on the detection function fitted to the distance data. Estimated detection probabilities within $100 \mathrm{~m}$ were $0.58 \pm 0.05$ for the observer and $0.46 \pm 0.04$ for the acoustic recorder. Most of the birds missed by the acoustic recorder ( $91 \%$ of 415$)$ were at distances $>100 \mathrm{~m}$. Among the 38 individuals missed within $100 \mathrm{~m}, 21(55 \%)$ were silent and detected only by visual observation. In other cases, multiple individuals of the same species were singing and thus underestimated from the recordings and others were simply not discernible on the recordings.

\section{Relative Abundance Models by Group}

The total number of birds detected across all species was best explained by an additive model that included the main effects of survey method and all 3 shrub characteristics, which had $72 \%$ of the support within the candidate model set $\left(\mathrm{AIC}_{c} \mathrm{w}_{\mathrm{i}}=0.72\right.$; Table 2). On average, the acoustic recorder detected fewer total birds than the field observer $\left(\beta_{\text {Method }}=-0.56 \pm 0.05 \mathrm{SE}\right)$; detections for both methods increased strongly with maximum shrub height $\left(\beta_{\mathrm{MaxHt}}=\right.$ $0.16 \pm 0.02$; Fig. $3 \mathrm{~A})$, moderated slightly by increases in total

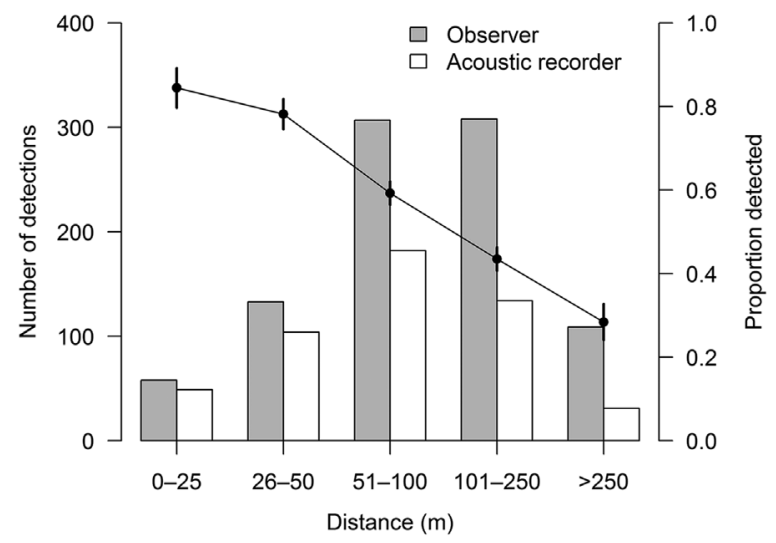

Figure 2. Total numbers of birds (all species combined) detected by a trained field observer (filled bars) and on simultaneous acoustic recordings (open bars) relative to distance from the survey point during 10-min point counts of tundra-breeding birds at 59 sites on the Seward Peninsula, northwestern Alaska, USA, 2014. Solid symbols and line indicate the proportion $( \pm \mathrm{SE})$ of birds detected by the observer that were also detected on the acoustic recording within each distance interval, given the assumption that vocalizations of the birds closest to the recording device were most likely to be recorded. 
Table 2. Model selection for effects of survey method (field observer vs. acoustic recorder) and shrub characteristics on counts of breeding birds by species group and on species richness in tundra habitats at 59 sites on the Seward Peninsula, northwestern Alaska, USA, 2014. Characteristics of shrubs modeled at each site include maximum height (MaxHt), average percent cover (Cover), and a visual obstruction index (VO). We present number of parameters $(K)$, Akaike's Information Criterion corrected for small sample size (AIC $)$, difference in $\mathrm{AIC}_{c}$ between model and top-ranked model in candidate set $(\Delta \mathrm{AIC})$, model weight $\left(w_{i}\right)$, cumulative model weight within candidate set, and log likelihood (LL) for each model. Only models with $\Delta \mathrm{AIC}<5$ are shown.

\begin{tabular}{|c|c|c|c|c|c|c|}
\hline Model & $K$ & $\mathrm{AIC}_{c}$ & $\Delta \mathrm{AIC}_{c}$ & $w_{i}$ & Cumulative $w_{i}$ & $\mathbf{L L}$ \\
\hline \multicolumn{7}{|l|}{ All birds } \\
\hline Method + MaxHt + Cover + VO & 5 & 742.26 & 0 & 0.72 & 0.72 & -365.86 \\
\hline Method + MaxHt + Cover & 4 & 744.28 & 2.02 & 0.26 & 0.99 & -367.96 \\
\hline \multicolumn{7}{|l|}{ Shorebirds } \\
\hline Method + VO & 3 & 335.80 & 0 & 0.40 & 0.40 & -164.80 \\
\hline Method + VO + MaxHt & 4 & 337.12 & 1.32 & 0.21 & 0.60 & -164.38 \\
\hline Method × VO & 4 & 337.73 & 1.92 & 0.15 & 0.76 & -164.69 \\
\hline Method $+\mathrm{VO}+$ Cover & 4 & 337.94 & 2.14 & 0.14 & 0.89 & -164.79 \\
\hline Method $+\mathrm{VO}+\mathrm{MaxHt}+$ Cover & 5 & 339.03 & 3.22 & 0.08 & 0.97 & -164.24 \\
\hline \multicolumn{7}{|l|}{ Thrushes and bluethroat } \\
\hline Method + MaxHt + Cover + VO & 5 & 361.43 & 0 & 0.96 & 0.96 & -175.44 \\
\hline \multicolumn{7}{|l|}{ Lapland longspur } \\
\hline Method + MaxHt + Cover & 4 & 205.18 & 0 & 0.68 & 0.68 & -98.41 \\
\hline Method + MaxHt + Cover + VO & 5 & 206.69 & 1.50 & 0.32 & 1.00 & -98.08 \\
\hline \multicolumn{7}{|l|}{ Old and New World warblers } \\
\hline Method + MaxHt + Cover & 4 & 388.08 & 0 & 0.73 & 0.73 & -189.86 \\
\hline Method + MaxHt + Cover + VO & 5 & 390.05 & 1.97 & 0.27 & 1.00 & -189.76 \\
\hline \multicolumn{7}{|l|}{ Sparrows } \\
\hline Method + Cover + MaxHt & 4 & 519.97 & 0 & 0.67 & 0.67 & -255.81 \\
\hline Method + Cover + MaxHt + VO & 5 & 521.61 & 1.64 & 0.29 & 0.96 & -255.54 \\
\hline \multicolumn{7}{|l|}{ Redpolls } \\
\hline Method + MaxHt + VO & 4 & 397.34 & 0 & 0.41 & 0.41 & -194.49 \\
\hline Method + MaxHt + Cover + VO & 5 & 397.67 & 0.33 & 0.35 & 0.76 & -193.57 \\
\hline Method + Cover + VO & 4 & 399.39 & 2.05 & 0.15 & 0.91 & -195.52 \\
\hline Method + MaxHt & 3 & 401.41 & 4.07 & 0.05 & 0.96 & -197.60 \\
\hline \multicolumn{7}{|l|}{ Species richness } \\
\hline Method + MaxHt + Cover + VO & 5 & 565.81 & 0 & 0.78 & 0.78 & -277.64 \\
\hline Method + MaxHt + Cover & 4 & 568.47 & 2.66 & 0.21 & 0.98 & -280.06 \\
\hline
\end{tabular}

shrub cover $\left(\beta_{\text {Cover }}=0.005 \pm 0.001\right)$ and decreases in visual obstruction $\left(\beta_{\mathrm{VO}}=-0.04 \pm 0.02\right)$.

Counts of 6 species of shorebirds were pooled into a single shorebird group (Table 1). The field observer and acoustic recorder detected 100 and 52 individual shorebirds, respectively. The top model included the main effects of survey method and visual obstruction and had $40 \%$ of the relative support of the data (Table 2). Additional parameters for shrub height, cover, and an interaction effect between method and visual obstruction were uninformative (sensu Arnold 2010) in other models; thus, the top model essentially received all of the support in the candidate set. Counts of shorebirds were lower for the acoustic recorder $\left(\beta_{\text {Method }}=-0.65 \pm 0.17\right)$ and decreased as visual obstruction of the surrounding vegetation increased $\left(\beta_{\mathrm{VO}}=-0.23 \pm 0.06\right.$; Fig. 4A).

Three species of New World thrushes and the thrush-like Old World bluethroat (Luscinia svecica) were detected during point-count surveys (Table 1). The field observer detected 134 birds within the "thrush" group and the acoustic recorder detected 74. An additive model with the effects of survey method and all 3 shrub characteristics received virtually all of the support of the data (96\%; Table 2). The acoustic recorder detected fewer thrushes than the field observer $\left(\beta_{\text {Method }}=\right.$ $-0.59 \pm 0.14)$ and detections by both methods increased primarily with shrub height $\left(\beta_{\mathrm{MaxHt}}=0.41 \pm 0.06\right.$; Fig. $\left.3 \mathrm{~B}\right)$, moderated by increases in cover $\left(\beta_{\text {Cover }}=0.011 \pm 0.004\right)$ and decreases in visual obstruction $\left(\beta_{\mathrm{VO}}=-0.27 \pm 0.07\right)$.
The field observer and acoustic recorder detected 67 and 27 Lapland longspurs (Calcarius lapponicus), respectively, at the 59 survey sites. The best model had $68 \%$ of the support of the data and included additive effects of survey method, maximum shrub height, and shrub cover (Table 2). The next best model added visual obstruction, which proved to be an uninformative parameter ( $c f$. Arnold 2010); thus, the remainder of the support could also be attributed to the top-ranked model. Acoustic recorders detected fewer longspurs than the field observer on average $\left(\beta_{\text {Method }}=-0.91 \pm 0.23\right)$ and counts from both methods declined rapidly with both maximum shrub height $\left(\beta_{\mathrm{MaxHt}}=-1.63 \pm 3.2\right.$; Fig. $\left.3 \mathrm{C}\right)$ and total shrub cover $\left(\beta_{\text {Cover }}=-0.025 \pm 0.006\right)$.

The observer detected 6 species of New World warblers and the ecologically similar Old World arctic warbler (Phylloscopus borealis) across the 59 survey sites (Table 1). The field observer and acoustic recorder detected 130 and 86 warblers, respectively. An additive model with main effects of survey method, maximum shrub height, and shrub cover had the majority of support (73\%) and also garnered the remainder of the weight from the next best model, which added visual obstruction, an uninformative parameter (Table 2). The acoustic recorder detected fewer birds than the field observer $\left(\beta_{\text {Method }}=-0.41 \pm 0.14\right)$ and detections by both methods increased strongly with shrub height $\left(\beta_{\mathrm{MaxHt}}=0.60 \pm 0.06\right.$; Fig. $\left.3 \mathrm{D}\right)$ and less so with shrub cover $\left(\beta_{\text {Cover }}=0.019 \pm 0.004\right)$. 

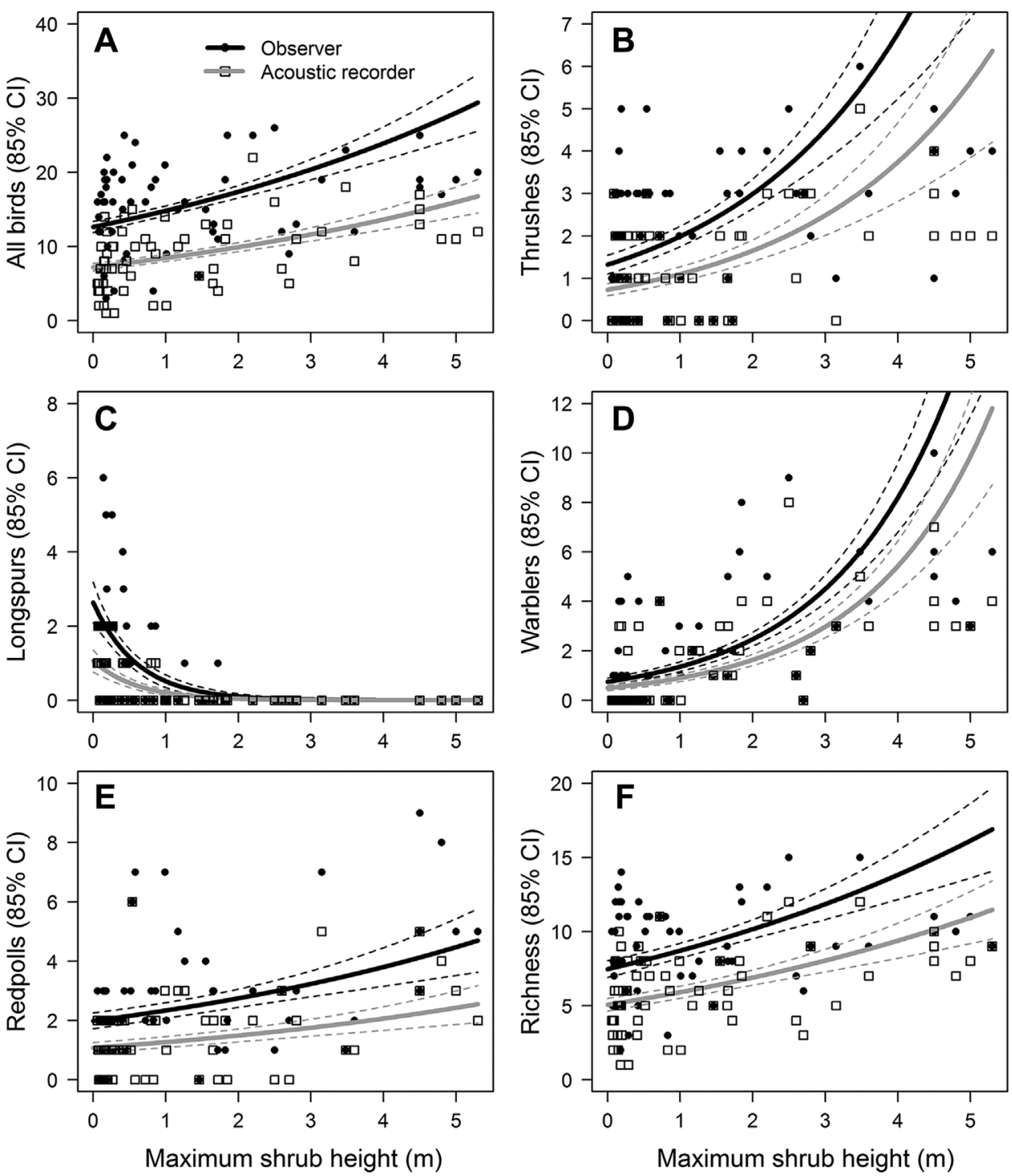

Figure 3. Predicted (lines $\pm 85 \% \mathrm{CI}$ ) and actual numbers of birds detected (individual symbols) by a field observer and an acoustic recorder relative to maximum shrub height (m) for (A) all birds, (B) New World thrushes plus bluethroat, (C) longspurs, (D) Old and New World warblers, (E) redpolls, and (F) number of species (naive richness) during 10-min point counts of tundra-breeding birds at 59 sites on the Seward Peninsula, northwestern Alaska, USA, 2014. Predicted relationships are based on the top-ranked model (lowest $\mathrm{AIC}_{c}$ value) in each candidate set with all other habitat covariates held at median values (Table 2).

Observations of 5 species of sparrows were combined into a single sparrow group at each survey site (Table 1). The field observer and acoustic recorder detected 260 and 175 sparrows, respectively, at all sites. The top-ranked model included additive effects of survey method, maximum shrub height, and shrub cover with $67 \%$ of the support; visual obstruction was again an uninformative parameter, resulting in $96 \%$ of cumulative support for the top model (Table 2). On average, acoustic recorders detected fewer sparrows per site than the field observer did ( $\beta_{\text {Method }}=-0.38 \pm 0.18$ ). Detections for both methods increased strongly with total shrub cover $\left(\beta_{\text {Cover }}=0.016 \pm 0.002\right.$; Fig. $\left.4 \mathrm{~B}\right)$ and maximum shrub height $\left(\beta_{\mathrm{MaxHt}}=0.12 \pm 0.04\right)$.

Counts of common and hoary redpolls (Acanthis flammea and $A$. hornemanni, respectively) were pooled into a single redpoll group (Table 1). The field observer detected 162 redpolls while 88 individual redpolls were identifiable from acoustic recordings. A single model with additive effects of survey method, maximum shrub height, and visual obstruction had $41 \%$ of the support; a model that also included shrub cover, an uninformative parameter, had another $35 \%$, thereby resulting in $76 \%$ of cumulative support for the top-ranked model (Table 2). Counts of redpolls were lower using acoustic recorders $\left(\beta_{\text {Method }}=\right.$ $-0.61 \pm 0.13)$, but increased with both maximum shrub height $\left(\beta_{\mathrm{MaxHt}}=0.16 \pm 0.04\right.$; Fig. $\left.3 \mathrm{E}\right)$ and visual obstruction $\left(\beta_{\mathrm{VO}}=0.12 \pm 0.075\right)$.

\section{Relative Species Richness}

At the transect level, the acoustic recorder detected slightly fewer species than did the field observer (acoustic recorder $=18.2 \pm 2.4 \mathrm{SD}$; observer $=21.4 \pm 4.1$; paired $t_{4}=2.76$, $P=0.05)$. At the scale of the individual survey point, acoustic recorders detected $2.9 \pm 1.9$ fewer species on average than 

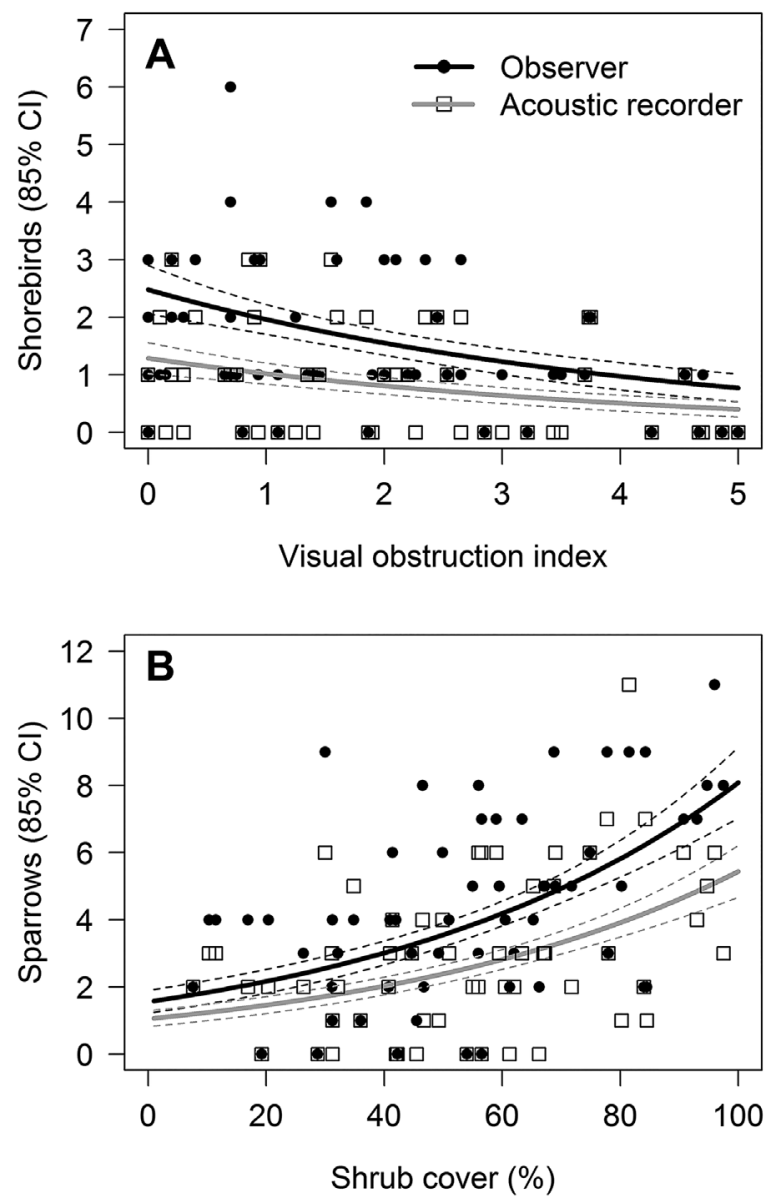

Figure 4. Predicted (lines $\pm 85 \% \mathrm{CI}$ ) and actual numbers of birds detected (individual symbols) by a field observer and an acoustic recorder for (A) shorebirds relative to the visual obstruction index for total vegetation and (B) sparrows relative to total shrub cover (\%) during 10-min point counts of tundra-breeding birds at 59 sites on the Seward Peninsula, northwestern Alaska, USA, 2014. Predicted relationships are based on the top-ranked model (lowest $\mathrm{AIC}_{c}$ value) in each candidate set with all other habitat covariates held at median values (Table 2).

the field observer did (paired $t_{58}=11.9, P<0.001$ ). An additive model with main effects of survey method and all 3 shrub characteristics received the majority of support in the candidate set (78\%). The additive model excluding visual obstruction carried most of the remaining support (Table 2). Species counts were lower for acoustic recorders $\left(\beta_{\text {Method }}\right.$ $=-0.39 \pm 0.07)$ and increased strongly with maximum shrub height $\left(\beta_{\mathrm{MaxHt}}=0.15 \pm 0.03\right.$; Fig. $\left.3 \mathrm{~F}\right)$, moderated by slight increases in shrub cover $\left(\beta_{\text {Cover }}=0.006 \pm 0.002\right)$ and decreases in visual obstruction $\left(\beta_{\mathrm{VO}}=-0.06 \pm 0.03\right)$.

\section{DISCUSSION}

We evaluated the performance of a commercially available acoustic recording device relative to a human field observer when conducting point-count surveys across tundra habitats of northwestern Alaska. We found that a trained human observer nearly always detected more birds than the acoustic recorder. However, despite variation across sites in several shrub characteristics, which strongly influence avian abundance in tundra ecosystems (Kessel 1979, 1989), the negative bias in relative abundance remained consistent between methods. Similarly, the acoustic recorder almost always detected fewer species than the field observer did, both at individual survey points and across entire transects, but differences between methods remained consistent relative to shrub conditions. The lack of a significant interaction effect between survey method and shrub characteristics on numbers of species or individuals counted within any species group suggested that detectability with the 2 methods was affected similarly by habitat conditions. Thus, the 2 methods should yield similar ecological inferences about the tundra-breeding avian community.

Differences in numbers of species and individuals detected by the 2 methods could largely be attributed to the smaller effective area sampled by acoustic recorders relative to that sampled by human observers in tundra habitats, although a few discrepancies were due to inability of the acoustic devices to detect nonvocalizing birds or the analyst's underestimation of multiple singing individuals at a given survey point. In contrast, one novel species and a few individuals of several other species missed by the field observer were subsequently detected on recordings. Hence, these comparisons suggest that studies using acoustic recorders to assess diversityhabitat associations in bird communities should account for potential disparities in sampling area, missed detections of silent birds, and underestimation of abundant species; this could be accomplished through a comparative study such as ours at a subsample of sites. Acoustic recordings can serve, however, to validate estimates of species richness derived from point counts by accounting for species that may have been overlooked in the field. Thus, simultaneous use of recordings and distance estimation by field observers can provide a powerful combination of methods to examine patterns of species abundance and richness across a varied landscape.

Overall, our results support previous research in other ecosystems finding utility of acoustic recorders for avian monitoring and research. Several studies at lower latitudes have demonstrated that recording devices are just as effective as or better than human observers at evaluating avian diversity and relative abundance (Haselmayer and Quinn 2000, Hobson et al. 2002, Acevedo and Villanueva-Rivera 2006, Celis-Murillo et al. 2009, Campbell and Francis 2012). In contrast, others have shown that human observers are more effective at detecting birds and provide less biased estimates of species richness than automated recording devices (Hutto and Stutzman 2009, Tegeler et al. 2012, Venier et al. 2012, Sidie-Slettedahl et al. 2015). Variable survey protocols have been cited to explain such discrepancies in utility of recording devices (Klingbeil and Willig 2015). The relative effectiveness of acoustic recorders is likely determined by site- and survey-specific environmental conditions (e.g., vegetation density, weather) and bird community of study.

The effective survey distance is an important consideration when designing point-count protocols for avian monitoring and research (Ralph et al. 1995). Effective survey distances vary by habitat, species, and survey 
conditions (Faanes and Bystrak 1981, Alldredge et al. 2007, Simons et al. 2007), suggesting regional or site-specific evaluation is necessary. Our data agree with previous studies finding that the proportion of birds detected by the field observer that are also detected by an acoustic recorder declines with distance from the survey point (Acevedo and Villanueva-Rivera 2006, Tegeler et al. 2012, Venier et al. 2012). Relative to the field observer, the acoustic recorder accounted for most birds occurring within $100 \mathrm{~m}$ of the survey point (80\%), but much lower detection rates beyond $100 \mathrm{~m}(48 \%)$ suggest limited utility of recording devices outside this range in tundra habitats. Similar results were found in a study of anurans in tundra meadows in subarctic Canada (Mannan et al. 2014). Given the relatively low densities of tundra-breeding birds, the efficiency of acoustic recorders at northern latitudes is much lower than that in temperate or tropical ecosystems in terms of numbers of individuals and species recorded. Thus, studies envisioned for monitoring tundra ecosystems with acoustic recorders should carefully assess the number of sites needed to estimate a target parameter with the desired precision.

Acoustic recorders sometimes outperform human field observers in detecting species in areas of high species richness and abundance because recordings can be replayed to distinguish between overlapping calls within and among species (Haselmayer and Quinn 2000, Acevedo and Villanueva-Rivera 2006). A drawback of the sole use of recorders, however, is that ensuing estimates of species richness are compromised by the lack of a defined area of inference. Periods of high bird activity often result in a lower proportion of total birds detected by a point-count observer as a result of overlapping songs and increased difficulty of detection as singing frequency increases and quick identifications must be made (Bystrak 1981, Bart and Schoultz 1984, Haselmayer and Quinn 2000, Hutto and Stutzman 2009). Arctic and subarctic habitats tend to have lower avian abundance and diversity relative to those in temperate and tropical regions (e.g., MacArthur 1972, Hawkins et al. 2003). Relatively low bird densities on our study areas reduced the initial count-recording frenzy that results from large numbers of active and vocalizing birds during the dawn chorus. Celis-Murillo et al. (2009) found that acoustic recorders provided a more accurate pattern of temporal bird detection throughout the recording period because recordings during high bird activity could be replayed to determine the exact minute a species or individual was first detected. Although activity periods are most intense during the early morning hours, the continuous daylight of the subarctic summer likely acts to reduce the intensity of the dawn chorus when compared with areas at lower latitudes (Ashley et al. 2013, Steiger et al. 2013).

Vegetation density and structure affect the abundance and probability of detection for many species of birds (McShea and Rappole 1997, Pacifici et al. 2008). As expected, bird counts at our study sites were influenced by shrub conditions for all bird groups we evaluated, a pattern we recently confirmed more broadly across the Seward Peninsula (Thompson et al. 2016). Importantly, however, statistically significant interactions between survey method and shrub characteristics were not supported for our models of individual counts. Both survey methods yielded similar inference regarding the effect of shrub conditions on relative abundance and species richness for all groups considered. Thus, our data suggest that acoustic recorders may have utility for studies evaluating the ecological patterns of relative abundance for most tundra-breeding passerines and shorebirds. Similar findings of relative performance of acoustic recorders for other avian communities in variable ecosystems suggest broad utility of recording devices for monitoring and research (Hobson et al. 2002, Hutto and Stutzman 2009, Celis-Murillo et al. 2012, Tegeler et al. 2012, Klingbeil and Willig 2015).

We have previously shown that raw species counts (i.e., naïve species richness) recorded by field observers can result in biased and often incorrect inferences regarding the influence of shrubs on species richness in tundra habitats and recommended that site-specific detection probabilities be incorporated into estimates (McNew and Handel 2015). In this study, we found significant associations between one or more shrub characteristics and naive species richness and abundance estimates for all species groups at the study sites. Maximum height of shrubs was the strongest correlate of overall species richness and abundance for 5 of 7 groups of birds considered, which confirms the importance of vegetation height and vertical structural diversity to birds in Alaska and elsewhere (MacArthur and MacArthur 1961; Kessel 1979, 1989, 1998). All bird groups responded positively to increases in shrub vegetation except shorebirds and longspurs, both of which select open meadows or dwarf shrub habitat for nesting (Kessel 1989). The amount of leaf area (Pacifici et al. 2008) or woody vegetation in otherwise open habitat (Weller et al. 2012) can strongly influence both detection probability and actual abundance of birds; therefore, it is important to use analytical methods that account for detectability effects at the site level to draw proper ecological inference about species abundance and richness (e.g., Royle and Dorazio 2008, Amundson et al. 2014). In addition, although we analyzed detections for guilds of birds because of limited sample sizes in this initial study, individual species within these guilds are likely to exhibit species-specific responses, some of which may be nonlinear relative to shrub characteristics. Such relationships should be investigated with a more robust data set (cf. Thompson et al. 2016).

The distribution and structure of vegetation types in boreal and Arctic ecosystems have been changing rapidly in response to climatic changes, with significant implications for avian abundance, biodiversity, and life-history phenology (Hinzman et al. 2005; Marcot et al. 2015; Stralberg et al. 2015, 2016). Carefully designed deployments of acoustic recorders may provide a cost-effective technique for monitoring ecosystem-level changes to bird communities. An optimal sampling strategy can be derived from estimates of time and costs involved in purchasing, deploying, and retrieving recorders; conducting point counts; and analyzing the recordings. Field costs will be 
dictated by accessibility of the sampling sites and level of desired precision of the estimates, which will in turn depend upon species abundance and variability across the study area. Time required to analyze recordings will depend upon species richness and abundance at each site and will be minimized if the analyst is familiar with the birds and dialects of the area. Even if data collected by automated recording devices cannot be analyzed immediately because of time constraints or lack of funding, subsets can be analyzed and the full data set can be archived for future analysis (Hobson et al. 2002).

In conclusion, our results suggest that acoustic recorders have utility for avian monitoring and research in the tundra ecosystems of Alaska and elsewhere. The time and expense required to use human observers to conduct point-count surveys in wilderness areas, coupled with the paucity of trained observers, brevity of the breeding season, and inaccessibility of remote wilderness areas, greatly restrict the capacity of a monitoring program based solely on such surveys. Acoustic recorders are relatively inexpensive and, once deployed, can provide nearly continuous survey data for an entire breeding season. Programmed, replicated recordings at fine temporal resolution (e.g., hourly, daily) can produce high-quality survey data sets suitable to estimate occupancy, abundance, and species richness using hierarchical models, as well as site-specific phenology of migration and breeding activity. Conducting point-count surveys simultaneously with a subset of acoustic recordings will allow direct assessment of detection probability and effective sampling area relative to vegetation and other site-specific characteristics, if distance sampling is used and vocalization behavior is recorded. This combined analytical approach will enable use of the more extensive acoustical data set to estimate densities and species richness (including nonvocal species) relative to site characteristics. Digitally archived acoustic recordings over time can provide records of changes to bird communities relative to management treatments, environmental changes, or other factors of interest. As technology advances and new acoustic recorders are developed, it will be important, particularly for long-term monitoring programs, to calibrate the units relative to detection distances to account for potential changes over time in effective sampling area.

\section{ACKNOWLEDGMENTS}

We thank R. M. Richardson for essential help in the field, particularly with collecting habitat data, and S. J. Thompson for assistance in data analysis, insightful discussions, and review of the manuscript. We also thank Associate Editor C. Boal, J. M. Pearce, and 2 anonymous reviewers for helpful suggestions that improved the manuscript. This work is part of the U.S. Geological Survey's (USGS) Changing Arctic Ecosystem Initiative and was supported by funding from the Wildlife Program of the USGS Ecosystem Mission Area. Use of any trade names is for descriptive purposes only and does not imply endorsement by the U.S. Government.

\section{LITERATURE CITED}

Acevedo, M. A., and L. J. Villanueva-Rivera. 2006. Using automated digital recording systems as effective tools for the monitoring of birds and amphibians. Wildlife Society Bulletin 34:211-214.

Alldredge, M. W., T. R. Simons, and K. H. Pollock. 2007. Factors affecting aural detections of songbirds. Ecological Applications 17:948-955.

Amundson, C. L., J. A. Royle, and C. M. Handel. 2014. A hierarchical model combining distance sampling and time removal to estimate detection probability during avian point counts. Auk 131:476-494.

Arnold, T. W. 2010. Uninformative parameters and model selection using Akaike's information criterion. Journal of Wildlife Management 74:1175-1178.

Ashley, N. T., I. Schwabl, W. Goymann, and C. L. Buck. 2013. Keeping time under the midnight sun: behavioral and plasma melatonin profiles of free-living Lapland longspurs (Calcarius lapponicus) during the Arctic summer. Journal of Experimental Zoology Part A: Ecological Genetics and Physiology 319:10-22.

Bart, J., and J. D. Schoultz. 1984. Reliability of singing bird surveys: changes in observer efficiency with avian density. Auk 101:307-318.

Buckland, S. T., D. R. Anderson, K. P. Burnham, J. L. Laake, D. L. Borchers, and L. Thomas. 2001. Introduction to distance sampling: estimating abundance of biological populations. Oxford University Press, New York, New York, USA.

Burnham, K. P., and D. R. Anderson. 2002. Model selection and multimodel inference: a practical information-theoretic approach. Second edition. Springer, New York, New York, USA.

Burnham, K. P., S. T. Buckland, J. L. Laake, D. L. Borchers, T. A. Marques, J. R. B. Bishop, and L. Thomas. 2004. Further topics in distance sampling. Pages 307-392 in S. T. Buckland, D. R. Anderson, K. P. Burnham, J. L. Laake, D. L. Borchers, and L. Thomas, editors. Advanced distance sampling. Oxford University Press, New York, New York, USA.

Bystrak, D. 1981. The North American Breeding Bird Survey. Studies in Avian Biology 6:34-41.

Campbell, M., and C. M. Francis. 2012. Using microphone arrays to examine effects of observers on birds during point count surveys. Journal of Field Ornithology 83:391-402.

Celis-Murillo, A., J. L. Deppe, and M. F. Allen. 2009. Using soundscape recordings to estimate bird species abundance, richness, and composition. Journal of Field Ornithology 80:64-78.

Celis-Murillo, A., J. L. Deppe, and M. P. Ward. 2012. Effectiveness and utility of acoustic recordings for surveying tropical birds. Journal of Field Ornithology 83:166-179.

Faanes, C. A., and D. Bystrak. 1981. The role of observer bias in the North American Breeding Bird Survey. Studies in Avian Biology 6:353-359.

Furnas, B. J., and R. L. Callas. 2015. Using automated recorders and occupancy models to monitor common forest birds across a large geographic region. Journal of Wildlife Management 79:325-337.

Hammond, T., and J. Yarie. 1996. Spatial prediction of climatic state factor regions in Alaska. Ecoscience 3:490-501.

Hanson, H. C. 1953. Vegetation types in northwestern Alaska and comparisons with communities in other Arctic regions. Ecology 34:111-140.

Haselmayer, J., and J. S. Quinn. 2000. A comparison of point counts and sound recording as bird survey methods in Amazonian Southeast Peru. Condor 102:887-893.

Hawkins, B. A., E. E. Porter, and J. A. F. Diniz-Filho. 2003. Productivity and history as predictors of the latitudinal diversity gradient of terrestrial birds. Ecology 84:1608-1623.

Hinzman, L. D., N. D. Bettez, W. R. Bolton, F. S. Chapin, M. B. Dyurgerov, C. L. Fastie, B. Griffith, R. D. Hollister, A. Hope, H. P. Huntington, A. M. Jensen, G. J. Jia, T. Jorgenson, D. L. Kane, D. R. Klein, G. Kofinas, A. H. Lynch, A. H. Lloyd, A. D. McGuire, F. E. Nelson, W. C. Oechel, T. E. Osterkamp, C. H. Racine, V. E. Romanovsky, R. S. Stone, D. A. Stow, M. Sturm, C. E. Tweedie, G. L. Vourlitis, M. D. Walker, D. A. Walker, P. J. Webber, J. M. Welker, K. S. Winker, and K. Yoshikawa. 2005. Evidence and implications of recent climate change in northern Alaska and other Arctic regions. Climatic Change 72:251-298.

Hobson, K. A., R. S. Rempel, G. Hamilton, B. Turnbull, and S. L. V. Wilgenburg. 2002. Acoustic surveys of birds using electronic recordings: new potential from an omnidirectional microphone system. Wildlife Society Bulletin 30:709-720. 
Hutto, R. L., and R. J. Stutzman. 2009. Humans versus autonomous recording units: a comparison of point-count results. Journal of Field Ornithology 80:387-398.

Kessel, B. 1979. Avian habitat classification for Alaska. Murrelet 60:86-94.

Kessel, B. 1989. Birds of the Seward Peninsula, Alaska. University of Alaska Press, Fairbanks, USA.

Kessel, B. 1998. Habitat characteristics of some passerine birds in western North American taiga. University of Alaska Press, Fairbanks, USA.

Klingbeil, B. T., and M. R. Willig. 2015. Bird biodiversity assessments in temperate forest: the value of point count versus acoustic monitoring protocols. PeerJ 3:e973.

MacArthur, R. H. 1972. Geographical ecology: patterns in the distribution of species. Princeton University Press, Princeton, New Jersey, USA.

MacArthur, R. H., and J. W. MacArthur. 1961. On bird species diversity. Ecology 42:594-598.

Mannan, R. N., G.Perry, D. E. Andersen, and C.W. Boal. 2014. Call broadcasting and automated recorders as tools for anuran surveys in a subarctic tundra landscape. Journal of North American Herpetology 2014:47-52.

Marcot, B. G., M. T. Jorgenson, J. P. Lawler, C. M. Handel, and A. R. DeGange. 2015. Projected changes in wildlife habitats in Arctic natural areas of northwest Alaska. Climatic Change 130:145-154.

McNew, L., C. Handel, J. Pearce, T. DeGange, L. Holland-Bartels, and M. Whalen. 2013. Changing Arctic ecosystems: the role of ecosystem changes across the boreal-Arctic transition zone on the distribution and abundance of wildlife populations. USGS Fact Sheet 2013-3054. http://pubs.usgs. gov/fs/2013/3054/. Accessed 19 Jun 2017.

McNew, L. B., and C. M. Handel. 2015. Evaluating species richness: biased ecological inference results from spatial heterogeneity in detection probabilities. Ecological Applications 25:1669-1680.

McShea, W. J., and J. H. Rappole. 1997. Variable song rates in three species of passerines and implications for estimating bird populations. Journal of Field Ornithology 68:367-375.

Pacifici, K., T. Simons, and K. Pollock. 2008. Effects of vegetation and background noise on the detection process in auditory avian point-count surveys. Auk 125:600-607.

R Core Team. 2013. R: a language and environment for statistical computing. R Foundation for Statistical Computing, Vienna, Austria. https://www.r-project.org/. Accessed 28 Apr 2016.

Ralph, C. J., J. R. Sauer, and S. Droege. 1995. Monitoring bird populations by point counts. General Technical Report PSW GTR-149. U.S. Department of Agriculture, Forest Service, Pacific Southwest Research Station, Albany, California, USA.

Rempel, R. S., K. A. Hobson, G. Holborn, S. L. Van Wilgenburg, and J. Elliott. 2005. Bioacoustic monitoring of forest songbirds: interpreter variability and effects of configuration and digital processing methods in the laboratory. Journal of Field Ornithology 76:1-11.

Robel, R. J., J. N. Briggs, A. D. Dayton, and L. C. Hulbert. 1970. Relationships between visual obstruction measurements and weight of grassland vegetation. Journal of Range Management 23:295-297.

Royle, A. J., and R. M. Dorazio. 2008. Hierarchical modeling and inference in ecology. Academic Press, San Diego, California, USA.

Sidie-Slettedahl, A. M., K. C. Jensen, R. R. Johnson, T. W. Arnold, J. E. Austin, and J. D. Stafford. 2015. Evaluation of autonomous recording units for detecting 3 species of secretive marsh birds. Wildlife Society Bulletin 39:626-634.

Simons, T. R., M. W. Alldredge, K. H. Pollock, and J. M. Wettroth. 2007. Experimental analysis of the auditory detection process on avian point counts. Auk 124:986-999.

Steiger, S. S., M. Valcu, K. Spoelstra, B. Helm, M. Wikelski, and B. Kempenaers. 2013. When the sun never sets: diverse activity rhythms under continuous daylight in free living Arctic-breeding birds. Proceedings of the Royal Society B: Biological Sciences 280:20131016.

Stralberg, D., S. M. Matsuoka, A. Hamann, E. M. Bayne, P. Solymos, F. K. A. Schmiegelow, X. Wang, S. G. Cumming, and S. J. Song. 2015. Projecting boreal bird responses to climate change: the signal exceeds the noise. Ecological Applications 25:52-69.

Stralberg, D., S. M. Matsuoka, C. M. Handel, F. K. A. Schmiegelow, A. Hamann, and E. M. Bayne. 2016. Biogeography of boreal passerine range dynamics in western North America: past, present, and future. Ecography 39:1-17. doi:10.1111/ecog.02393

Swanson, J. D., M. Schuman, and P. C. Scorup. 1985. Range survey of the Seward Peninsula reindeer ranges, Alaska. U.S. Department of Agriculture, Soil Conservation Service, Anchorage, Alaska, USA.

Tegeler, A. K., M. L. Morrison, and J. M. Szewczak. 2012. Using extendedduration audio recordings to survey avian species. Wildlife Society Bulletin 36:21-29.

Thompson, S. J., C. M. Handel, and L. B. McNew. 2017. Autonomous acoustic recorders reveal complex patterns in avian detection probability. Journal of Wildlife Management 81:1228-1241.

Thompson, S. J., C. M. Handel, R. M. Richardson, and L. B. McNew. 2016. When winners become losers: nonlinear responses of Arctic birds to increasing woody vegetation. PLoS ONE 11(11):e0164755.

Venier, L. A., S. B. Holmes, G. W. Holborn, K. A. McIlwrick, and G. Brown. 2012. Evaluation of an automated recording device for monitoring forest birds. Wildlife Society Bulletin 36:30-39.

Weller, F., G. Blackwell, and H. Miller. 2012. Detection probability for estimating bird density on New Zealand sheep \& beef farms. New Zealand Journal of Ecology 36:371-381.

Yoshikawa, K., and L. D. Hinzman. 2003. Shrinking thermokarst ponds and groundwater dynamics in discontinuous permafrost near Council, Alaska. Permafrost and Periglacial Processes 14:151-160.

\section{Associate Editor: Boal.}

\section{SUPPORTING INFORMATION}

Additional supporting information may be found in the online version of this article at the publisher's web-site.

Table S1. Total number of birds detected and missed by field observers and acoustic recorders during 10 -min point-count surveys on tundra habitats at 59 sites on the Seward Peninsula, northwestern Alaska, USA, June 2014. 